PAPP-A and second-trimester uterine artery Doppler pulsatility index as markers of pre-eclampsia", Ultrasound in Obstetrics and Gynecology: The Official Journal of the International Society of Ultrasound in Obstetrics and Gynecology, 29 (2), pp. 128-134.

3. Poon L., Kametas N., Chelemen T., et al. (2010), "Maternal risk factors for hypertensive disorders in pregnancy: a multivariate approach", Journal of human hypertension, 24 (2), pp. 104-110.

4. Parra-Cordero M., Rodrigo R., Barja P., et al. (2013), "Prediction of early and late pre-eclampsia from maternal characteristics, uterine artery Doppler and markers of vasculogenesis during first trimester of pregnancy", Ultrasound in Obstetrics \& Gynecology, 41 (5), pp. 538-544.

5. Bodnar L. M., Ness R. B., Markovic N., et al. (2005), "The risk of preeclampsia rises with increasing prepregnancy body mass index", Annals of epidemiology, 15 (7), pp. 475-482.

6. Sohlberg S., Stephansson 0. ., Cnattingius S., et al. (2012), "Maternal body mass index, height, and risks of preeclampsia", American journal of hypertension, 25 (1), pp. 120-125.

7. Bartsch E., Medcalf K. E., Park A. L., et al. (2016), "Clinical risk factors for pre-eclampsia determined in early pregnancy: systematic review and meta- analysis of large cohort studies", Bmj, 353

8. Organization W. H. (1995), "Physical status: The use of and interpretation of anthropometry, Report of a WHO Expert Committee".

9. Velauthar L., Plana M., Kalidindi M., et al. (2014), "First-trimester uterine artery Doppler and adverse pregnancy outcome: a meta-analysis involving 55974 women", Ultrasound in Obstetrics \& Gynecology, 43 (5), pp. 500-507.

\title{
KHẢO SÁT CHẤT LƯợNG CUộC SỐNG CỦA NGƯờI BỆNH UNG THƯ PHỔI KHÔNG TẾ BÀO NHỎ TRƯỚC VÀ SAU XẠ TRI TẠI KHOA XẠ LỒNG NGỰC, BỆNH VIỆN K
}

\begin{abstract}
TÓM TẮT.
Mục tiêu :Khảo sát chất lương cuộc sống của người bệnh ung thư phổi không tế bào nhỏ (UTPKTBN) trước và sau xạ trị tại khoa Xa Lồng ngực, Bệnh viện K. Đối tượng, phướng pháp :105 người bểnh được chẩn đoán là Unng thư nguyên phát tai phổi giai đoạn III điều trị tia xa. Sử dụng thang điểm Bộ câu hỏi EORTC QLQ-C30 để khảo sát chất lượng cuộc sống của người bệnh tại 2 thời điểm trước và sau xạ trị. Kết quả: Trước xạ trị điểm trung bình CLCS cao nhất thuộc về lĩnh vực "Chức năng cảm xúc" với 72,8 điểm, xếp thứ hai là "Chức năng nhận thức" đạt 72,0 điểm, còn thấp nhất là lĩnh vực "Chức năng hoạt động" 31,7 điểm. Sau xa trị điểm trung bình về lĩnh vực chức năng lần lượt là: nhận thức $(77,2)$, cảm xúc $(76,7)$, xã hội $(71,8)$, thể chất $(67,1)$, hoạt động $(31,2)$. Chất lượng cuộc sống chung ở mức trung bình cả 2 thời điểm nghiên cứu là 54,0 điểm. Lĩnh vực triệu chứng của người bệnh UTPKTBN giai đoạn III kể cả trước và sau xạ trị có điểm trung bình lần lượt là: mệt mỏi $(68,2 ; 65,8)$, đau $(54,4 ; 43,6)$, chán ằn $(53,0$; $50,2)$, mất ngủ $(52,5 ; 28,5)$ và khó thở $(31,7 ; 25,9)$. Các triêu chứng buốn nôn, táo bón và tiêu chảy ít gặp với điểm trung bình dưới 20 điểm cả 2 thời điểm. Vấn đề khó khăn tài chính của đối tượng nghiên cứu có điểm ở mức trung bình $(60,4 ; 63,8)$. Kết luận: Với nhóm đối tượng nghiên cứu thì vấn đề chức nẳng của người bệnh tốt, vấn đề về sức khỏe ở mức độ trung bình.
\end{abstract}

*Bệnh viện $K$

Chịu trách nhiệm chính: Vũ Thị Thu Nga

Email: indijon09@gmail.com

Ngày nhận bài: 14.9.2021

Ngày phản biện khoa học: 10.11.2021

Ngày duyệt bài: 16.11.2021
Vũ Thị Thu Nga*

Tư khóa: Ung thư phổi không tế bào nhỏ; Chất lượng cuộc sống; Xạ trị

\section{SUMMARY \\ SURVEY ON THE QUALITY OF LIFE OF NON-SMALL CELL LUNG CANCER PATIENTS BEFORE AND AFTER RADIATION AT THE THORACIC RADIOLOGY DEPARTMENT, K HOSPITAL}

Objectivity: To survey the quality of life of patients with non-small cell lung cancer (NSCLC) before and after radiation therapy at the Department of Thoracic Radiation, K Hospital. Subjects and methods: 105 patients were diagnosed as: Primary cancer in the lung stage III treated with radiation. Using the EORTC QLQ-C30 questionnaire scale to survey the quality of life of patients at 2 time points before and after radiation therapy. Results: Before radiation therapy, the highest average score of $\mathrm{QOL}$ belonged to the field of "Emotional function" with 72.8 points, second was "Cognitive function" with 72.0 points, and the lowest was in the field of "Emotional function" with 72.8 points. "Active function" 31.7 points. After radiotherapy, the average scores in functional areas are: cognitive (77.2), emotional (76.7), social (71.8), physical (67.1), activity ( 31.2). Overall quality of life at the average of both study points was 54.0 points. The common symptom areas of patients with stage III NSCLC, both before and after radiotherapy, are fatigue $(68.2 ; 65.8)$, pain (54.4; 43.6), anorexia (53.0). ; 50.2), insomnia (52.5; $28.5)$ and shortness of breath (31.7; 25.9). Symptoms of nausea, constipation and diarrhea were uncommon with an average score of less than 20 points in both time points. The problem of financial difficulty of the 
research subjects has a rather high average score $(60.4 ; 63.8)$. Conclusion: With the study group, the functional problem of the patient is good, the health problem is at an average level.

Keywords: Non-small cell lung cancer; Life quality; Radiotherapy.

\section{I. ĐẶT VẤN ĐỀ}

Ung thư phổi là một trong 3 ung thư thường gặp nhất và là nguyên nhân gây tử vong hàng đầu do ung thư ở phạm vi toàn cầu. Theo Globocan 2020, tại Việt Nam ước tính mỗi năm có khoảng 22.000 trường hợp mới mắc $(16.000$ nam và 6.000 nữ), trong đó tử vong khoảng gần 19.600 người [1].

Trong quá trình điều trị bệnh ung thư phổi, tình trạng bệnh lý, phương pháp điều trị làm rối loạn một số chức năng của cơ thể ít nhiều cũng ảnh hưởng lên chất lượng cuộc sống của người bệnh ở nhiều khía cạnh khác nhau về hoạt động thể chất, tình trạng tâm lý và giao tiếp hòa nhập xã hội.

Hiện nay, cùng với sự phát triển của xã hội và nhu cầu của con người, chất lượng cuộc sống của người bệnh ung thư đã được quan tâm nhiều hơn và trở thành mục tiêu nghiên cứu của nhiều đề tài về ung thư nói chung trên thế giới và tại Việt Nam.

Mục tiêu của nghiên cứu này nhằm khảo sát chất lượng cuộc sống của người bệnh ung thư phổi không tế bào nhỏ trong quá trình điều trị tia xạ. Kết quả này có thể được sử dụng như kế hoạch chăm sóc của điều dưỡng và chăm sóc để thúc đẩy sự tự quản lý và cung cấp chăm sóc hỗ trợ người bệnh ung thư phổi trong thời gian người bệnh điều trị tại khoa, từ đó giúp họ trở nên tự tin hơn và tham gia vào nhiều hoạt động xã hội.

\section{II. ĐỐl TƯỢNG VÀ PHƯƠNG PHÁP NGHIÊN CỨU}

1. Đối tượng nghiên cứu. 105 người bệnh được chẩn đoán là Ung thư nguyên phát tại phổi giai đoạn III điều trị tia xa tại khoa Xa Lồng ngực, Bệnh viện $\mathrm{K}$ từ tháng 4 đến tháng 9 năm 2021.

- Tiểu chuẩn lựa chọn

- Chẩn đoán xác định ung thư nguyên phát tai phổi

- Giải phẫu bệnh là ung thư phổi không tế bào nhỏ (UTPKTBN) bản 8

- Chẩn đoán giai đoạn III theo AJCC phiên

- Có chỉ định và điều trị tia xạ

- Người bệnh điều trị đủ liệu trình theo đúng phác đồ

- Người bệnh đồng thuận tham gia nghiên cứu
- Tiêu chuẩn loại trừ

- Người bệnh khổng thỏa mãn các tiêu chuẩn lựa chon

- NB có bệnh ung thư thứ hai kèm theo

- Người bệnh tự ý bỏ dở điều trị

- Người bệnh không đồng ý tham gia nghiên cứu

2. Phương pháp nghiên cứu:

- Thiết kế nghiên cứu: Nghiên cứu mô tả cắt ngang

- Khảo sát chất lượng cuộc sống của bệnh nhân nghiên cứu:

Chất lượng cuộc sống của người bệnh ung thư phổi trong nghiên cứu được đánh giá bằng Bộ câu hỏi tự điền EORTC QLQ-C30 bao gồm các câuu hỏi đánh giá chức năng và triệu chứng liên quan tới ung thư phổi và ung thư nói chung. Chia câu hỏi thành 4 mức độ từ 1 (không có) đến 4 (rất nhiều) [8]

- Cách tính điểm EORTC QLQ-C30:

Cách tính thang điểm này theo hướng dẫn của nhóm nghiên cứu về chất lượng

cuộc sống của Tổ chức Nghiên cứu và Điều trị Ung thư Châu Âu (Nhóm tác giả của Bộ câu hỏi EORTC QLQ-C30) [8]

Điểm số bô công cu EORTC QLQ-C30 của các vấn đề thay đổi từ 0 đến 100 và có ý nghĩa như sau:

- Vấn đề chức năng: điểm số càng cao chức năng càng tốt, kết luận vấn đề chức năng tốt.

- Vấn đề về triệu chứng: điểm số càng cao triệu chứng càng nặng, kết luận vấn đề sức khỏe xấu.

- Điểm thô: trung bình điểm các câu hỏi cùng vấn đề.

Điểm thô: RawScore $(\mathrm{RS})=(\mathrm{Q} 1+\mathrm{Q} 2+\ldots+$ Qn)/n

- Điểm chuẩn hóa: điểm thô được tính trên tỉ lệ 100 (theo công thức)

- Điểm lĩnh vực chức năng: Score $=\{1-(\mathrm{RS}$ 1)/3\} $\times 100$

- Điểm lĩnh vực triệu chứng: Score $=\{(R S$ -

1)/3\} $\times 100$

- Điểm sức khỏe tổng quát: $\quad$ Score $=\{(R S$ -

1)/6\}×100

Đánh giá chất lượng cuộc sống bệnh nhân tại 2 thời điểm: Trước và sau điều trị tia xạ

- Phân tích và xử lý số liệu. Các số liệu tại các thời điểm nghiên cứu (trước xa trị và sau xạ tri) được nhâpp và xử lý bằng phẩn mềm SPSS 20. Tại mỗi thời điểm nghiên cứu, điểm CLCS của mỗi chỉ số được thống kê để tìm giá trị trung bình cho mỗi chỉ số của từng thời điểm.

\section{KẾT QUẢ NGHIÊN CỨU}

1. Đặc điểm người bệnh trong nghiên cứu 
Bảng 1: Phân bố người bệnh UTPKTBN theo khoảng tuổi và giới

\begin{tabular}{|c|c|c|c|}
\hline \multirow{2}{*}{ Tuổi } & Nội dung & $\begin{array}{l}\text { Số lượng } \\
\text { (n= 105) }\end{array}$ & $\begin{array}{c}\text { Tỉ lệ } \\
\text { (\%) }\end{array}$ \\
\cline { 2 - 4 } & $30-59$ & 44 & 42 \\
\hline \multirow{3}{*}{ Tuối trung bình: 61} & 58,7 \\
\hline \multirow{2}{*}{ Giới } & Nam & 85 & 81 \\
\cline { 2 - 4 } & Nữ & 20 & 19 \\
\hline
\end{tabular}

Tuổi của nhóm người bệnh nghiên cứu phân bổ từ 30 - 77, chủ yếu trong độ tuổi trên 60 (58\%). Tuổi trung bình của nhóm là 60,7.

Trong mẫu nghiên cứu, nam chiếm tỷ lệ cao (81\%) hơn nữ (19\%).

Phân loại người bệnh theo giai đoạn bệnh: Người bệnh UTPKTBN ở giai đoạn IIIB chiếm tỷ lệ cao $(59 \%)$, giai đoạn IIIA và IIIC tương đương nhau (lần lượt 20\%, 21\%).

Phương pháp điều trị: Tỷ lệ người bệnh xạ trị đơn thuần cao hơn (60\%) hóa xạ trị đồng thời $(40 \%)$

$100 \%$ người bệnh trong nhóm nghiên cứu tuân thủ điều trị hết liệu trình.

2. Chất lượng cuộc sống của người bệnh UTPKTBN trước và sau điều trị tia Xa

Bảng 2: Điểm trung binh chẩt lượng cuộc sống về chức năng thể chât và chức năng hoạt động của bệnh nhân UTPKTBN $(n=105)$

\begin{tabular}{|c|c|c|c|}
\hline \multirow{2}{*}{ Câu } & \multirow[b]{2}{*}{ Nội dung } & \multicolumn{2}{|c|}{$\begin{array}{c}\text { Điểm trung } \\
\text { bình }\end{array}$} \\
\hline & & \multirow{2}{*}{$\begin{array}{c}\begin{array}{c}\text { Trước } \\
\text { xạ trị }\end{array} \\
59,8 \\
\end{array}$} & \multirow{2}{*}{\begin{tabular}{|c|c}
$\begin{array}{c}\text { Sau } \\
\text { xạ } \\
\text { trị }\end{array}$ \\
67,1 \\
\end{tabular}} \\
\hline & Thể chất & & \\
\hline C1 & $\begin{array}{l}\text { Gặp khó khăn khi thực } \\
\text { hiện các công việc gắng } \\
\text { sức }\end{array}$ & 37,3 & 42,8 \\
\hline $\mathrm{C} 2$ & $\begin{array}{c}\text { Thấy khó khăn khi đi bộ } \\
\text { một quãng dài }\end{array}$ & 49,2 & 52,5 \\
\hline C3 & $\begin{array}{l}\text { Thấy khó khăn khi đi bộ } \\
\text { một quãng ngắn }\end{array}$ & 72,9 & 77,3 \\
\hline C4 & $\begin{array}{l}\text { Nằm nghỉ trên giường hay } \\
\text { trên ghế suốt ngày }\end{array}$ & 61,4 & 78,8 \\
\hline C5 & $\begin{array}{c}\text { Cân giúp đõ̃ khi ăn mặc, } \\
\text { tắm giặt, vệ sinh }\end{array}$ & 78,6 & 84,1 \\
\hline \multicolumn{2}{|r|}{ Hoạt động } & 31,7 & 31,2 \\
\hline C6 & $\begin{array}{c}\text { Bị hạn chế trong việc làm } \\
\text { hoặc trong các công việc } \\
\text { hàng ngày }\end{array}$ & 32,8 & 31,9 \\
\hline C7 & $\begin{array}{l}\text { Bị hạn chế theo đuổi các } \\
\text { sơ thích hay trong các } \\
\text { hoạt động giải trí khác }\end{array}$ & 30,7 & 30,5 \\
\hline
\end{tabular}

Tại 2 thời điểm với chức năng thể chất điểm trung bình ở nội dung "Cần giúp đõ̃ khi ăn mặc, tắm giă̆t, vê sinh" cao nhất $(78,6 ; 84,1)$ và thấp nhất là "Gặp khó khăn khi thực hiện các công việc gắng sức" $(37,3 ; 42,8)$. Chức năng hoạt động có điểm trung bình của "Bị hạn chế theo đuổi các sở thích hay trong các hoạt động giải trí khác" là 30,7.

Bảng 3: Điểm trung binh chất lượng cuộc sống về chức năng cảm xúc, nhận thức và xã hội của người bệnh UTPKTBN $(n=105)$

\begin{tabular}{|c|c|c|c|}
\hline \multirow{2}{*}{ Câu } & \multirow{2}{*}{ Nội dung } & \multicolumn{2}{|c|}{$\begin{array}{l}\text { Điếm trung } \\
\text { bình }\end{array}$} \\
\hline & & $\begin{array}{l}\text { Trước } \\
\text { xạ trị }\end{array}$ & $\begin{array}{c}\text { Sau xạ } \\
\text { trị }\end{array}$ \\
\hline \multicolumn{2}{|r|}{ Cảm xúc } & 72,8 & 76,7 \\
\hline $\mathrm{C} 21$ & Cảm thấy căng thằng & 72,3 & 82,8 \\
\hline $\mathrm{C} 22$ & Có lo lắng & 66,5 & 70,2 \\
\hline C23 & Cảm thấy dề bưc tức & 64,8 & 65,4 \\
\hline C24 & Cảm thây buồn chán & 87,7 & 88,5 \\
\hline \multicolumn{2}{|r|}{ Nhận thức } & 72,0 & 77,2 \\
\hline $\mathrm{C} 20$ & Khó tâp trung & 71,5 & 79,3 \\
\hline C25 & $\begin{array}{c}\text { Khó khăn khi phải nhớ lại } \\
\text { môt sư viêc }\end{array}$ & 72,4 & 75,2 \\
\hline \multicolumn{2}{|r|}{ Xã hội } & 69,0 & 71,8 \\
\hline C26 & $\begin{array}{l}\text { Tình trạng thế lực hoăc } \\
\text { việc điều trị gây cản trở } \\
\text { đến cônn viếc gia đình }\end{array}$ & 62,5 & 65,7 \\
\hline C27 & $\begin{array}{l}\text { Tình trạng thế lực hoăcc } \\
\text { việc điều trị gây cản trở } \\
\text { đến hoat đông xã hôi }\end{array}$ & 75,4 & 77,9 \\
\hline
\end{tabular}

Điểm trung bình của chức năng cảm xúc, nhận thức và chức năng xã hội ở mức khá cao (62,5 - 87,7 điểm) cả 2 thời điểm.

Bảng 4: Điểm trung bình chất lượng cuộc sống về sức khỏe chung và chât lướng cuộc sống chung của người bệnh UTPKTBN $(n=105)$

\begin{tabular}{|l|c|c|c|}
\hline Câu & Nội dung & \multicolumn{2}{|c|}{ Điểm trung bình } \\
\cline { 3 - 4 } & $\begin{array}{c}\text { Trước xạ } \\
\text { trị }\end{array}$ & $\begin{array}{c}\text { Sau xạ } \\
\text { trị }\end{array}$ \\
\hline C29 & $\begin{array}{c}\text { Tự đánh giá về sức } \\
\text { khỏe chung của } \\
\text { mình }\end{array}$ & 45,9 & 46,2 \\
\hline C30 & $\begin{array}{c}\text { Tự đánh giá về chất } \\
\text { lượng cuộc sống } \\
\text { chung của minh }\end{array}$ & 54,0 & 54,0 \\
\hline
\end{tabular}

Điểm trung bình CLCS về nội dung đánh giá sức khỏe chung của người bênh trước 45,9 điểm và sau xạ trị là 46,2 điểm. Tự đánh giá về chất lượng cuộc sống chung ở mức trung bình (54,0 điểm). 
Bảng 5: Điểm trung binh CLCS lĩnh vức triệu chứng và vấn đề khó khăn tài chính của người bệnh UTPKTBN ( $n=105)$

\begin{tabular}{|c|c|c|c|}
\hline \multirow{2}{*}{ Câu } & \multirow{2}{*}{ Nội dung } & \multicolumn{2}{|c|}{$\begin{array}{c}\text { Tiếm trung } \\
\text { bình }\end{array}$} \\
\cline { 3 - 4 } & & $\begin{array}{c}\text { Trước } \\
\text { xạ trị }\end{array}$ & $\begin{array}{c}\text { Sau } \\
\text { xạ trị }\end{array}$ \\
\hline C10,12,18 & Mệt mỏi & 68,2 & 65,8 \\
\hline C9,19 & Cảm giác đau & 54,4 & 43,6 \\
\hline C11 & Mất ngủ & 52,5 & 28,5 \\
\hline C8 & Khó thở & 31.7 & 25,9 \\
\hline C13 & Chán ăn & 53,0 & 50,2 \\
\hline C14,15 & Buồn nôn, nôn & 2,3 & 1,9 \\
\hline C16 & Táo bón & 12,7 & 13,0 \\
\hline C17 & Tiêu chảy & 2,8 & 2,5 \\
\hline C28 & Khó khăn tài chính & 60,4 & 63,8 \\
\hline Truón
\end{tabular}

Trước xạ trị lĩnh vực triệu chứng của ngườ bệnh UTPKTBN có điểm số cao nhất là mệt mỏi $(68,2)$, sau đến là đau $(54,4)$, chán ăn $(53,0)$, mất ngủ $(52,5)$ và khó thở $(31,7)$. Sau xạ trị điểm trung bình chất lượng cuộc sống lĩnh vực triệu chứng lần lượt là mệt mỏi $(65,8)$, chán ăn $(50,2)$, đau $(43,6)$, mất ngủ $(28,5)$, khó thở $(25,9)$. Các triẹu chứng buồn nôn, táo bón và tiêu chảy có điểm trung bình dưới 20 điểm cả 2 thời điểm. Vấn đề khó khăn tài chính của đối tượng nghiên cứu có điểm trung bình khá cao (60,4 điểm trước và 63,8 điểm sau xạ trị).

\section{BÀN LUÂN}

1. Đặc điểm người bệnh trong nghiên cứu. Trong tổng số 105 người bênh được phỏng vấn, tỉ lệ người bệnh là nam giới có tỷ lệ cao (81\%) hơn nữ giới $(19 \%)$, tỷ lệ này phù hợp với các nghiên cứu về tỷ lệ mắc ung thư tại Việt Nam [1]. Điều này có thể được giải thích là bển cạnh một số yếu tố như cơ địa, di truyền thì nam giới có thói quen và lối sống kém lành mạnh hơn phụ nữ, như hút thuốc, uống rượu cùng với đó lại ít quan tâm đến việc khám sức khỏe định kỳ, dẫn đến nguy cơ mắc bệnh ung thư phổi cao hơn.

Tuổi của bệnh nhân chủ yếu $>60$ tuổi (chiếm tỷ lệ $58 \%$ ) điều này cũng hoàn toàn phù hợp với các nghiên cứu dịch tễ học ung thư [5].

Về điều kiện kinh tế gia đình, có tới khoảng $11,5 \%$ người bệnh thuộc hộ nghèo/cận nghèo. Đây là một vấn đề cần được lưu tâm bởi vì chi phí để điểu trị cho bệnh ung thư nói chung và ung thư phổi nói riêng là không nhỏ, điều này có thể gây ra những khó khăn nhất định cho bản thân người bệnh và gia đình của họ.

2. Chất lượng cuộc sống của người bệnh UTPKTBN trước và sau xạ trị. Chức năng thể chất và hoạt động thể hiện ở Bảng 2 có kết quả là điểm trung bình của chức năng thể chất ở mức trung bình với 59,8 điểm trước xạ trị và 67,1 sau xạ trị, điểm số này thấp hơn so với điểm số trong nghiên cứu của Phạm Cẩm Phương và Mai Trọng Khoa (2016) là 80,5 và 86,7 [4]. Chức năng hoạt động không được tốt với điểm trung bình là 31,7 và không thay đổi đáng kể ở 2 thời điểm trước và sau xạ trị, tương đồng với nghiên cứu của Nguyễn Thanh Mai (2019) [4].

Bảng 3 cho thấy thời điểm trước xạ trị điểm trung bình của chức năng cảm xúc, nhận thức và chức năng xã hội ở mức khá cao $(62,5-87,7$ điểm) và được cải thiện hơn ở thời điểm sau xa trị $(65,4$ - 88,5 điểm), thể hiện nhóm người bệnh trong nghiên cứu này có các chức năng cảm xúc, chức năng nhận thức và chức năng xã hội tốt, tương đồng với nghiên cứu của Phạm Cẩm Phương và Mai Trọng Khoa (2016) [3].

Sức khỏe tổng quát và CLCS ở Bảng 5 cho thấy điểm trung bình CLCS của nhóm người bệnh nghiên cứu ở mức thấp 45,9 điểm trước xa trị và 46,2 điểm sau xa tri. Tự đánh giá CLCS là 54,0 điểm. Điểm số chất lượng cuộc sống của người bệnh cho thấy các vấn đề cần được quan tâm theo dõi và chăm sóc như: Cảm giác nôn, buồn nôn; đau; trong khi sự hỗ trợ từ bạn bè là hạn chế. Mức hài lòng về đời sống tinh thần là tốt, trong khi đó khả năng hoạt động của người bệnh bị ung thư tham gia nghiên cứu là khá thấp, họ suy giảm khá nhiêu về năng lực hoạt động bởi việc phải nằm trong bệnh viện, tình trạng sức khoẻ hạn chế và phải trải qua thời gian điêu trị dài ngày.

Triệu chứng và vấn đề khó khăn tài chính: Một trong những nguyên nhân chủ yếu khiến nhân bệnh nhân ung thư phải vào viện là gặp phải các vấn đề về triệu chứng của bệnh, mức độ nă̆ng, nhẹ của các triệu chứng ảnh hưởng đển chất lượng cuộc sống của bệnh nhân. Vì vậy ngoài các vấn đề về chức năng bộ công cụ EORTC QLQ - C30 đã đề cập đến 8 vấn đề triệu chứng thường gặp ở bệnh nhân ung thư là: mệt mỏi, chán ăn, đau, nôn, khó thở, tiêu chảy và táo bón và vấn đề khó khăn tài chính để đánh giá CLCS của bệnh nhân ung thư. Trong nghiên cứu này lĩnh vực triệu chứng của người bệnh UTPKTBN giai đoạn III kể cả trước và sau xạ trị có điểm trung bình cho từng triệu chứng là: mệt mỏi $(68,2 ; 65,8)$, đau $(54,4 ; 43,6)$, chán ăn $(53,0 ; 50,2)$, mất ngủ $(52,5 ; 28,5)$ và khó thơ $(31,7 ; 25,9)$. Các triệu chứng buồn nôn, táo bón và tiêu chảy ít gặp với điểm trung bình dưới 20 điểm cả 2 thời điểm. Vấn đề khó khăn tài chính 
của đối tượng nghiên cứu có điểm trung bình khá cao $(60,4 ; 63,8)$.

Các nghiên cứu trên những đối tượng khác nhau cho kết quả cũng khác nhau: Nguyễn Thành Lam và cộng sự (2019) [2] nghiên cứu trên 327 người bệnh ung thư điều trị taii Trung tâm Ung bướu Thái Nguyên cho thấy điểm trung bình của các triệu chứng hay gặp là: đau $(63,3)$, mệt mỏi $(58,5)$, chán ăn $(49,6)$, mất ngủ $(47,8)$, khó khăn tài chính $(77,5)$. Tuy vậy, nhìn chung trung bình sức khỏe tổng quát của người bệnh ung thư đều tương đối thấp, các triệu chứng đau, mệt mỏi, chán ăn, mất ngủ đều hay gặp với điểm trung bình tương đối cao, ngược lại các triệu chứng ít gặp như tiêu chảy, táo bón, buồn nôn, nôn có điểm trung bình thấp.

\section{KẾT LUẬN}

Sau xạ trị điểm trung bình một số lĩnh vực chức năng cao hơn thời điểm trước xạ trị nhứ: cảm xúc $(72,8 ; 76,7)$, nhận thức $(72,0 ; 77,2)$, còn lînh vực "Chức năng hoạt động" không thay đổi đáng kể $(31,7 ; 31,2)$.

Chất lượng cuộc sống chung ở mức trung bình cả 2 thời điểm nghiên cứu là 54,0 điểm.

Lĩnh vực triệu chứng của người bệnh UTPKTBN giai đoạn III kể cả trước và sau xạ trị thường gặp có điểm trung bình là: mệt mỏi $(68,2 ; 65,8)$, đau $(54,4 ; 43,6)$, chán ăn $(53,0$; $50,2)$, mất ngủ $(52,5 ; 28,5)$ và khó thở $(31,7$; $25,9)$. Các triệu chứng buồn nôn, táo bón và tiêu chảy ít gặp với điểm trung bình dưới 20 điểm cả 2 thời điểm. Vấn đề khó khăn tài chính của đối tượng nghiên cứu ở mức trung bình $(60,4 ; 63,8)$.

\section{TÀI LIẸU THAM KHẢO}

1. Globocan 2020. https://gco.iarc.fr/ today/data/ factsheets/ populations/900-world-fact-sheets.

2. Nguyễn Thành Lam và cộng sự (2019), "Tình trạng đau và chất lượng cuộ́c sống của bệnh nhân ung thư điêu trị tại Trung tâm Ung bướu Thái Nguyên từ tháng 1- 6 năm 2019". Tạp chí thần kinh học Việt Nam số 28.

3. Phạm Cẩm Phương và Mai Trọng Khoa (2016), "Đánh giá chẩt lượng cuộc sống của bệnh nhân ung thư phổi không tế bào nhỏ được điêu trị thuốc ức chế TIROSINE KINASE tại Bệnh viện Bạch Mai". Tạp chí Y - Dược hơc quân sự số 1.

4. Nguyến Thanh Mai (Đề tài cơ sở 2019), "Chất lượng cuộc sống và các yễu tố liên quan của người bểnh ung thư phổi sau phẫu thuật"

5. Phạm Thị Hoàng Anh, Ngự̂̃n Mạnh Quốc, Nguyễn Bá Đức, Nguyễn Chấn Hùng (2001), "Tinh hình bệnh ung thư ở Việt Nam năm 2000". Tạp chí thông tin Y dược số 2 .

6. Trưan Bảo Ngọc, Bùi Diệu, Nguyễn Tuyết Mai (2012). Chất lươơng cuộc sống 71 bệnh nhân ung thư đâu cổ giai đoạn muộn sau hóa trị tuân tự sử dụng bộ câu hỏi EORTC QLQQ C-30 và QLQ-H\&Nं35. Tạp chí Ung thư hooc Viêt Nam.

7. Bừi Vũ Bình, Đố Thị Ânh, Dương Tiến Đỉnh và các cộng sự. (2015), Khảo sát chất lượng cuộc sống của bệnh nhân ung thư và một số yểu tố ảnh hưởng tại Bệnh viện Đại học Y Hà Nội năm 2015, Báo cáo Hội nghị khoà học chào mừng 65 năm truyền thống Bệnh viện Quần y 103, Hội nghị Khoa học điêu dưỡng, Hà Nội.

8. Bergman B, Aaronson NK, Ahmedzai $S$ et al. The EORTC QLQ-LC13: a modular supplement to the EORTC Core Quality of Life Questionnaire (QLQ-C30) for use in lung cancer clinical trials. EORTC Study Group on Quality of Life. Eur J Cancer. 1994, 30A (5), pp.635-642. 4

\section{KẾT QUẢ ĐIỀU TRỊ DỰ PHÒNG HUYẾT KHỐI TĨNH MẠCH CỦA WARFARIN VÀ RIVAROXABAN TRONG VÀ SAU PHẪU THUÂTT}

\section{TÓM TẮT}

Mục tiêu: Đánh giá kết quả điều trị dự phòng huyết khối tĩnh mạch của warfarin và rivaroxaban trong và sau phẫu thuật. Đối tượng và phương pháp nghiên cứu: Hồi cứu 10870 người bệnh phẫu thuật >18 tuổi từ 1/1/2017 đến 31/9/2018 được điều trị chống đông bằng warfarin hoặc rivaroxaban. Trong

\footnotetext{
${ }^{1}$ Trường Đại học Y Hà Nội

${ }^{2}$ Bệnh viện Đại học Y Hà Nội

Chịu trách nhiệm chính: Bùi Mỹ Hạnh

Email: buimyhanh@hmu.edu.vn

Ngày nhận bài: 13.9.2021

Ngày phản biện khoa học: 11.11.2021

Ngày duyệt bài: 17.11.2021
}

$$
\text { Bùi Mỹ Hạnh", }{ }^{1,2} \text { Lê Văn Tú }{ }^{1,2}
$$

đó 4191 NB dự phòng bằng warfarin và 6679 NB dự phòng bằng rivaroxaban. Kết quả nghiên cứu: Trong đợt nằm viện sau phẫu thuật có $37 / 6679$ $(0,6 \%)$ NB điều trị rivaroxaban và $52 / 4191(1,2 \%)$ NB điều trị warfarin xuất hiện HKTM (bao gồm cà tắc mach phổi và huyết khối tĩnh mạch chi dưới). Đồng thời sau ra viện 90 ngày có $36 / 6679(0,5 \%)$ NB dự phòng với rivaroxaban xuất hiên HKTM ít hơn 51/4191 $(1,2 \%)$ NB bệnh dự phòng với warfarin. Tỷ lệ có biến chứng xuất huyết ở nhóm dự phòng với warfarin nhiều hơn so với nhóm dự phòng với rivaroxaban $(7,3 \%$ và $4,2 \%)$ có ý nghĩa thống $k e ̂(p<0,05)$. Trong số biến chứng xuất huyết xuất hiện phần lớn là nhồi máu não $(3,7 \%$ trong nhóm dự phò̀ng với rivaroxaban và $5,9 \%$ trong nhóm dự phòng với warfarin) ngoài ra có xuất huyết tiêu hóa và một số xuất huyết khác. Kết luận: Rivaroxaban làm giảm tỷ lệ tái phát HKTM và khổng 